\title{
Gene expression profiling reveals underlying molecular mechanism of hepatoprotective effect of Phyllanthus niruri on thioacetamide-induced hepatotoxicity in Sprague Dawley rats
}

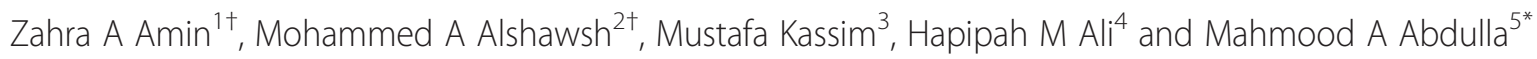

\begin{abstract}
Background: The liver plays an essential role in the body by regulating several important metabolic functions. Liver injury is associated with the distortion of these functions causing many health problems. Pharmaceutical drugs treat liver disorders but cause further damage to it. Hence, herbal drugs are used worldwide and are becoming increasingly popular.

Methods: The hepatoprotective activity of Phyllanthus niruri (PN) was evaluated against liver cirrhosis induced by thioacetamide (TAA) in male Sprague Dawley rats. Rats received intraperitoneal injections of thioacetamide (TAA, $200 \mathrm{mg} / \mathrm{kg}$, b.w. three times weekly) for eight weeks. Daily treatments with plant extract $(200 \mathrm{mg} / \mathrm{kg})$ were administered orally for eight weeks. At the end of the study, hepatic damage was evaluated by monitoring transforming growth factor (TGF $\beta$ ), collagen a1 (Colla1), matrix metalloproteinase-2 (MMP2) and tissue inhibitor of matrix metalloproteinase-1 (TIMP1) gene expression by real-time PCR. Moreover, different chromatographic techniques including column chromatography, thin layer chromatography, and Ultra Performance Liquid Chromatography (UPLC) with Liquid Chromatography/Mass Spectrometry (LC/MS) were used to isolate the active constituents of the plant.

Results: The results revealed that treatment with PN significantly reduced the effect of thioacetamide toxicity and exhibited effective hepatoprotective activity. The mechanism of the hepatoprotective effect of PN is proposed to be by normalizing ROSs. Additionally, PN treatment regulated the expression of TGF $\beta$, Colla1, MMP2, and TIMP1 genes. In the active fraction of $P$. niruri, the isolated chemical constituents were 4-O-caffeoylquinic acid and quercetin 3-O-rhamnoside.
\end{abstract}

Conclusions: The results of the present study indicate that PN ethanol extracts possess hepatoprotective activity that is most likely because of the isolated chemical constituents.

Keywords: Phyllanthus niruri, Hepatoprotective, Gene expression, Active constituents

\footnotetext{
* Correspondence: ammeen@um.edu.my

${ }^{\dagger}$ Equal contributors

${ }^{5}$ Department of Biomedical Science, Faculty of Medicine, Kuala Lumpur

50603, Malaysia

Full list of author information is available at the end of the article
} 


\section{Background}

Phyllanthus niruri has been used in folk medicine as an antipyretic, analgesic, or anti-inflammatory treatment, and treatment of other symptoms suggests antihistamine effects. Moreover, the decoction of the whole plant has been used orally against diarrhea and topically to treat jaundice. Crushed leaves together with leaves of Eupatorium odoratum and lime are applied on boils [1]. Previous studies have revealed the therapeutic potential of Phyllanthus niruri to treat genitourinary infections, venereal diseases, and kidney or bladder stones. Moreover, $P$. niruri is reported to act as a urinary inhibitor of calcium oxalate crystallization and an effective treatment for urolithiasis by interfering in the growth and aggregation of calcium oxalate crystals [2-4]. The reported antihyperuricemic action might be because of its uricosuric activity through an xanthine oxidase inhibitory effect [5].

Many reports in the literature have verified the protective activity of Phyllanthus niruri against various drug- and toxin-induced hepatic disorders. Earlier studies [6] have shown that extracts of $P$. niruri have demonstrated hepatoprotective activity against the carbon tetrachloride induced lipid peroxidation in the livers of rats, which was determined by raised serum enzyme levels. Although the effects of aqueous extracts of $P$. niruri against carbon tetrachloride $\left(\mathrm{CCL}_{4}\right)$-induced liver, kidney and testes injuries have been studied [7], Manjrekar et al. concluded that the hepatoprotective and antioxidant activity of this plant was associated with adverse effects on kidney and testes. In the study by Bhattacharjee et al. [8], the hepatoprotective potential of the protein isolated from $P$. niruri against $\mathrm{CCL}_{4}$-induced liver damage was investigated. These results suggested that this protein protected the liver against oxidative stress and stimulated liver repair mechanisms. Additionally, Harish et al. [6] investigated the antioxidant activity of extracts of $P$. niruri against $\mathrm{CCL}_{4}$-induced liver damage. They demonstrated that membrane lipid peroxidation (LPO) inhibition was confirmable by pre-treatment with the extracts.

In our previous research, we proved that $P$. niruri possesses hepatoprotective activity against thioacetamideinduced liver cirrhosis. Acute toxicity was studied, and the results demonstrated that $P$. niruri extract was non toxic when applied to SD rats. Significant differences were observed between thioacetamide-treated rats $(200 \mathrm{mg} / \mathrm{kg})$ and high or low dose (200 mg/kg and $100 \mathrm{mg} / \mathrm{kg}$ ) $P$. niruri-treated rats in the body and liver weights, total antioxidant capacity, liver biochemical parameters, oxidative stress enzyme and lipid peroxidation levels. Moreover, $P$. niruri treatment effectively restored the histological and morphological observations closer to their normal appearances [9].

The goal of this study was to study the mechanism that induces the hepatoprotective activity of Phyllanthus niruri ethanol extract in protecting liver cirrhosis induced by thioacetamide in Sprague Dawley rats by monitoring the expression of transforming growth factor beta (TGF $\beta 1$ ), tissue inhibitors of metalloproteinases (TIMP1), matrix metalloproteinase (MMP2), and collagen alpha (Coll $\alpha 1)$ gene expression by real-time PCR. Moreover, the active constituents of the Phyllanthus niruri were isolated by separating the crude extract into several fractions using flash column chromatography and thin layer chromatography. Subsequently, the immunomodulatory activity for all fractions was tested to examine their abilities to proliferate human peripheral blood mononuclear cells (PBMCs). LC/MS was performed on the fraction that exhibited higher proliferation activity on the PBMCs.

\section{Methods}

\section{Preparation of plant extract}

Phyllanthus niruri plant was gained from Ethno Resources Sdn Bhd, identified and a voucher specimen (voucher number KLU46618) was kept. By the method of Zahra et al. [10], a crude ethanol extract was prepared by drenching $100 \mathrm{~g}$ of it in $1000 \mathrm{~mL}$ of $95 \%$ ethanol $(1: 10 \mathrm{w} / \mathrm{v})$ for 72 hours at $25^{\circ} \mathrm{C}$. The mixture was filtered and distilled under reduced pressure at $45^{\circ} \mathrm{C}$ by a rotary evaporator. The crude extract was maintained at $-20^{\circ} \mathrm{C}$ until further experiments were done.

\section{Chemicals and apparatus}

In brief, 95\% (v/v) ethanol, filter paper (Whatman No. 1), Thioacetamide, xylazine, ketamine, formalin, hematoxylin, and eosin were purchased from Sigma-Aldrich (Gillingham, UK). RNAlater solution (Applied Biosystems, Foster City, CA, USA), QIAamp RNA blood mini kit (Qiagen, Germantown, MD, USA), RNase-free DNase set (Qiagen), agarose gels, Tris-borate-EDTA (10× TBE) (Applied Biosystems), ethidium bromide, loading dye (Promega, Madison, WI, USA) and a UV gel documentation system (Vilber Lourmat, Fisher Scientific Sdn Bhd). High Capacity RNA-to-cDNA Master Mix, TaqMan Fast Advanced Master Mix, ultrapure DNase-free water (Applied Biosystems) were used to perform the reverse transcription and real-time PCR. Transforming growth factor beta (TGF $\beta 1$ ), tissue inhibitors of metalloproteinases (TIMP1), matrix metalloproteinase (MMP2), collagen alpha (Coll 1 1), hypoxanthine phosphoribosyltransferase 1 (Hprt1), and peptidylprolyl isomerase A (Ppia) were the genes of interest.

Silica gel 60 powder $(0.063-0.200 \mathrm{~mm}, 70-230 \mathrm{mesh})$, silica gel F254 plates $(20 \times 20 \mathrm{~cm}, 0.2 \mathrm{~mm})$, HPLC grade n-hexane, HPLC grade ethyl acetate, HPLC grade methanol, HPLC grade acetonitrile were purchased from (Merck, Germany), a Kontes column $(2 \times 30 \mathrm{~cm})$ with an EYEL-4 pump (Rikakikai, Tokyo, Japan) and a Milli-Q water purification system (Millipore, Billerica, MA, USA) were used to perform the HPLC analysis. 


\section{Experimental design}

The animal protocol was agreed by the Ethics Committee for Animal Experimentation, Medicine Faculty, University Malaya, Kuala Lumpur, Malaysia, under Ethic number PM/28/08/2010/MAA (R). The animals were cared for according to the "Guide for the Care and Use of Laboratory Animals", published by the National Academy of Science. The animals were provided with water and standard pellet ad libitum.

Sprague Dawley rats (24 male) weighing 190-260 grams were divided into 3 groups randomly of 8 rats each. The experimental groups were as follows: healthy controls (vehicle control group), thioacetamide controls (liver cirrhosis control), and the $P$. niruri treatment group. The plant extract was suspended in Tween 20 (10\%) and administered by oral gavage $(5 \mathrm{~mL} / \mathrm{kg}$ body weight). Thioacetamide was suspended in $\mathrm{dH}_{2} \mathrm{O}(2 \mathrm{~mL} / \mathrm{kg}$ body weight) and injected intraperitoneally to the rats. Group no. 1 (normal group) treated daily with Tween 20 orally and injected with $\mathrm{dH}_{2} \mathrm{O}$ three times weekly intraperitoneally (ip) for two months. Group no. 2 (TAA group) treated daily with Tween 20 and injected with TAA $(200 \mathrm{mg} / \mathrm{kg}$ ) three times weekly for two months. The above mentioned procedure was following the method of Alshawsh et al. [11]. Group no. 3 (PN-treated group) treated daily with the PN extract $(200 \mathrm{mg} / \mathrm{kg}$ ) orally and injected with TAA $(200 \mathrm{mg} / \mathrm{kg})$ three times weekly for two months.

\section{Sample collection}

After two months, each rat was fasted for 24 hours prior to sacrificing. A perfusion was performed under ketamine and xylazine $(1: 10 \mathrm{v} / \mathrm{v})$ anesthesia, and rats were quickly sacrificed by exsanguination of the jugular vein. A small portion of the livers were kept immediately in an RNAlater solution (Applied Biosystems) for gene expression analysis and kept at $-80^{\circ} \mathrm{C}$ until the purification experiment was performed. The gene expression assays were performed using the following TaqMan gene expression workflow: RNA isolation and purification, RNA transcription RNA to cDNA, and amplification of cDNA and target genes by real-time PCR. The gene assays used in this study were transforming growth factor beta (TGF $\beta 1$ ), tissue inhibitors of metalloproteinases (TIMP1), matrix metalloproteinase (MMP2), and collagen alpha (Coll $\alpha 1$ ), and hypoxanthine phosphoribosyltransferase 1 (Hprt1) and peptidylprolyl isomerase A (Ppia) were used as housekeeping genes.

\section{Gene expression profile}

\section{RNA isolation and purification}

RNA was extracted from the frozen liver using a QIAamp RNA Blood Mini Kit following the manufacturer's protocol. Briefly, $30 \mathrm{mg}$ of frozen RNAlater-stabilized liver tissue was weighed immediately (without allowing the tissue to thaw), then disrupted and grinded by using a mortar and pestle. QIAshredder spin columns were used for homogenization and separation of the tissue lysates. The column digestion of DNA was performed during RNA purification using an RNase-free DNase set according to the manufacturer's instructions. Finally, total RNA was stored at $-70^{\circ} \mathrm{C}$ until further use.

RNA purity was quantified using a spectrophotometer using a $10 \mathrm{~mm}$ quartz cuvette. With a $40 \times$ dilution factor, absorbance was measured at 230, 260, 280, and $320 \mathrm{~nm}$, and the following ratios were calculated: 260/ 280 and $260 / 320$.

RNA integrity was measured by agarose gels electrophoresis. Electrophoresis buffer tris-borate-EDTA (10x TBA) was prepared to fill the electrophoresis tank and cast the gel. A $0.5 \%(\mathrm{w} / \mathrm{v})$ solution of agarose in electrophoresis buffer was prepared. Ethidium bromide was added to the molten gel to a final concentration $(0.5 \mu \mathrm{g} /$ $\mathrm{mL}$ ) and then mixed thoroughly by gentle swirling. A small-toothed comb (allows $1 \mu \mathrm{L}$ sample/well) was positioned on the plate to form complete wells. The $60^{\circ} \mathrm{C}$ agarose solution was poured into the mold and allowed to set at room temperature for 30-45 minutes. The gel was mounted into the tank, and the electrophoresis buffer was added to cover the gel at a depth of $1 \mathrm{~mm}$.

RNA samples $(1 \mu \mathrm{L}$ each) were loaded after mixing with the loading dye. Subsequently, the RNAs were allowed to migrate toward the positive anode. The gel ran for $30 \mathrm{mi}-$ nutes at $95 \mathrm{~V}$ until the migrated distance was $75 \%$ through the gel. The gels were examined under UV light to observe the discrete $18 \mathrm{~S}$ and $28 \mathrm{~S}$ ribosomal RNA bands.

\section{Reverse transcription of RNA to CDNA}

cDNA was synthesized using High Capacity RNA-to-cDNA Master Mix in a reaction plate according to the manufacturer's instructions.

\section{Amplification of $C D N A$ by real-time $P C R$}

Real-time PCR was performed using a StepOnePlus System and TaqMan Fast Advanced Master Mix (Applied Biosystems). The total reaction volume $(10 \mu \mathrm{L})$ consisted of the following: $1 \mu \mathrm{L}$ cDNA (20 ng), $5 \mu \mathrm{L}$ TaqMan Fast Advanced Master Mix, $0.5 \mu \mathrm{L}$ of each TaqMan Gene Expression Assay, and $3.5 \mu \mathrm{L}$ ultrapure DNase-free water. The cycle parameters were as follows: UNG incubation at $50^{\circ} \mathrm{C}$ for $2 \mathrm{~min}$, polymerase activation at $95^{\circ} \mathrm{C}$ for $20 \mathrm{~s}$, denaturation at $95^{\circ} \mathrm{C}$ for $1 \mathrm{~s}$ and then annealing and extension at $60^{\circ} \mathrm{C}$ for $20 \mathrm{~s}$.

\section{Real-time PCR data normalization}

The real-time PCR work was done in triplicate for each sample. Two endogenous control genes, hypoxanthine phosphoribosyltransferase 1 (Hprt1) and peptidylprolyl 
isomerase A (Ppia), were used for normalization. The comparative CT method was used to calculate to calculate the relative amount of the transcripts in all groups, and genes were normalized to the endogenous controls. The final value was normalized to the Hprt1 and Ppia genes and qualified to the normal control values of the investigated genes. The formula is as follows:

$$
\Delta \Delta \mathrm{CT}=\Delta \mathrm{CT}(\text { sample })-\Delta \mathrm{CT}(\text { normal })
$$

Where $\triangle \mathrm{CT}$ is the difference in $\mathrm{CT}$ between the targeted gene and housekeeping controls by minimizing the average $\mathrm{CT}$ of the controls. The fold-change calculated as: $\mathbf{2}^{-\Delta \Delta \mathbf{C T}}$.

\section{Chromatography profile}

\section{Flash column chromatography (FCC)}

Plant fractionations were performed following the method of Fraga et al. [12]. Flash column chromatography was performed on silica gel $60(0.063-0.200 \mathrm{~mm}, 70-230$ mesh) from (Merck, Germany) using a Kontes column $(2 \times$ $30 \mathrm{~cm}$ ) with an EYEL-4 pump (Rikakikai, Tokyo, Japan). The elution process to extract plant fractions $(1 \mathrm{~g} / 5 \mathrm{~mL}$ methanol) began with the most non-polar solvent (n-hexane), and then a continuous gradient elution (n-hexane ethyl acetate - methanol - acetonitrile) was applied that concluded with the most polar solvent $\left(\mathrm{dH}_{2} \mathrm{O}\right)$, which was purified by a Milli-Q water purification system (Millipore).

\section{Thin layer chromatography (TLC)}

The obtained fractions were dissolved in methanol at $10 \mathrm{mg} / \mathrm{mL}$ to perform thin layer chromatography (TLC) with silica gel F254 $(20 \times 20 \mathrm{~cm}, 0.2 \mathrm{~mm})$ plates. The analyses were achieved in the following: n-hexane ethyl acetate, ethyl acetate - methanol, methanol acetonitrile, and acetonitrile - water.

\section{Ultra Performance Liquid Chromatography (UPLC) and Liquid Chromatography/Mass Spectrometry (LC/MS)}

A Waters Synapt HDMS system in TOF-mode was used to perform Ultra Performance Liquid Chromatography (UPLC) and HDMS-mode was used to perform mass spectrometry that was equipped with an ACQUITY PDA Detector and ACQUITY UPLC BEH C ${ }_{18}$ column $(1.7 \mu \mathrm{m}, 2.1 \times 50 \mathrm{~mm})$.

The flow rate was $0.5 \mathrm{~mL} / \mathrm{min}$, and the injection volume was $3 \mu \mathrm{L}$. The analyses were performed using binary gradients of Milli-Q water (with $0.1 \%$ formic acid) (solvent A) and HPLC grade acetonitrile (with $0.1 \%$ formic acid) (solvent $B)$ with the following elution profile: from 0 min: $0 \%$ (B) in (A); 7 min: 100\% (B) in (A); $10 \mathrm{~min}: 100 \%$ (B) in (A); $11 \mathrm{~min}: 0 \%(\mathrm{~B})$ in (A).

\section{Statistical analysis and data management}

Real-time PCR data were analyzed using GenEx program. (GenEx software, www.multid.se); fold changes were calculated, and $T$-test was used to examine the differences between groups for all genes. "The Dictionary of Natural Products on DVD" software (CRC Press, Taylor and Francis Group, www.netbeans.org) was used to analyze the chromatography profiling data.

\section{Results}

\section{Integrity of RNA}

Total RNA was extracted from the liver tissues, and the quantity of RNA was determined by reading the absorbance at $260 \mathrm{~nm}$ spectrophotometrically with an ND2000 NanoDrop Spectrophotometer (Thermo Fisher Scientific, Wilmington, DE, USA). The ratio of the absorbance readings at $260 \mathrm{~nm}$ and $280 \mathrm{~nm}$ was used to indicate the quality of RNA. The $260 / 280$ ratio for our RNA preparation ranged from 1.6-2.1; these values suggested good quality RNA. The integrity of RNA was checked by agarose gel electrophoresis. Discrete $28 \mathrm{~S}$ and $18 \mathrm{~S}$ ribosomal RNA bands were obtained in each case. The 28S rRNA band was approximately twice as large as the $18 \mathrm{~S}$ rRNA band, indicating that the extracted RNA was intact and could be used in RT-PCR. Figure 1 shows a typical ethidium bromide-stained agarose RNA gel.

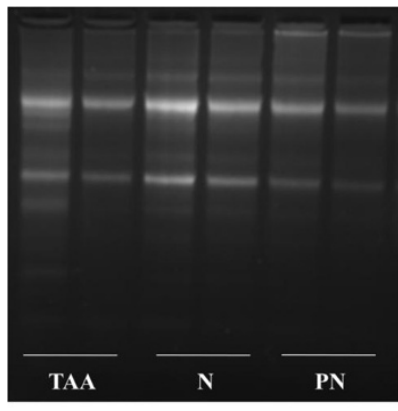

(A)

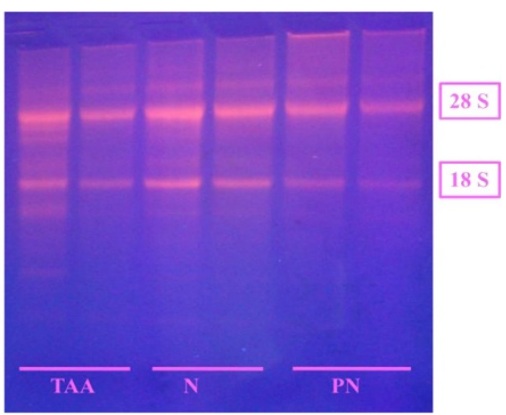

(B)

Figure 1 A typical ethidium bromide-stained agarose gel shows the integrity of the extracted RNA; $(\mathrm{A})$ visualized under a Vilber Lourmat gel documentation system (B) visualized under UV light. 


\section{Real-time PCR analysis}

$\mathrm{Ct}$ values of real-time PCR data were calculated using GenEX software and normalized to the reference genes HPRT1 and Ppia. The analysis showed significant differences in mRNA expression levels of the investigated genes between the controls and TAA- and PN-treated rats. In the control rats, the mRNA levels of TGF $\beta$, coll 1 1, MMP2 or TIMP1 were unchanged suggesting that the hepatic satellite cells (HSCs) were in their quiescent state (Figure 2). In the TAA-treated group, hepatic expression levels of all investigated genes were upregulated. The upregulation was significant at $(P<$ 0.01 ) in the TAA-treated group compared with the PNtreated group for the genes TGF $\beta \quad(1.677 \pm 0.120)$, Collo1 (47.062 \pm 7.716$)$ and MMP2 (14.500 \pm 3.528$)$. However, the difference was non-significant for TIMP1 $(1.738 \pm 0.486)$.

Oral administration of $\mathrm{PN}$ before cirrhosis induction prevented and resolved the activation of HSCs, and the remaining cells expressed decreased levels of TGF $\beta$, Coll $\alpha 1$, and MMP2 compared with the TAA-treated group as shown in Figure 2.

\section{Chromatography profile}

After crude extraction of $P$. niruri, the ethanol extract was objected to flash column chromatography to separate the constituents of the extracts according to molecular size, molecular mass, and polarity. Therefore, 12 fractions were obtained, and by performing thin layer chromatography, the subsequent fractions with the same retention factor and spot colors after visualizing under UV light at $240 \mathrm{~nm}$ and $360 \mathrm{~nm}$ were combined to yield five fractions (PNF1, PNF2, PNF3, PNF4, and PNF5). The best resolutions of plates were given by acetonitrilewater. Subsequently, the immunomodulatory activity for all fractions was tested to examine their abilities to proliferate human peripheral mononuclear cells (PBMCs). As shown in Figure 3, PN fractions showed high activities
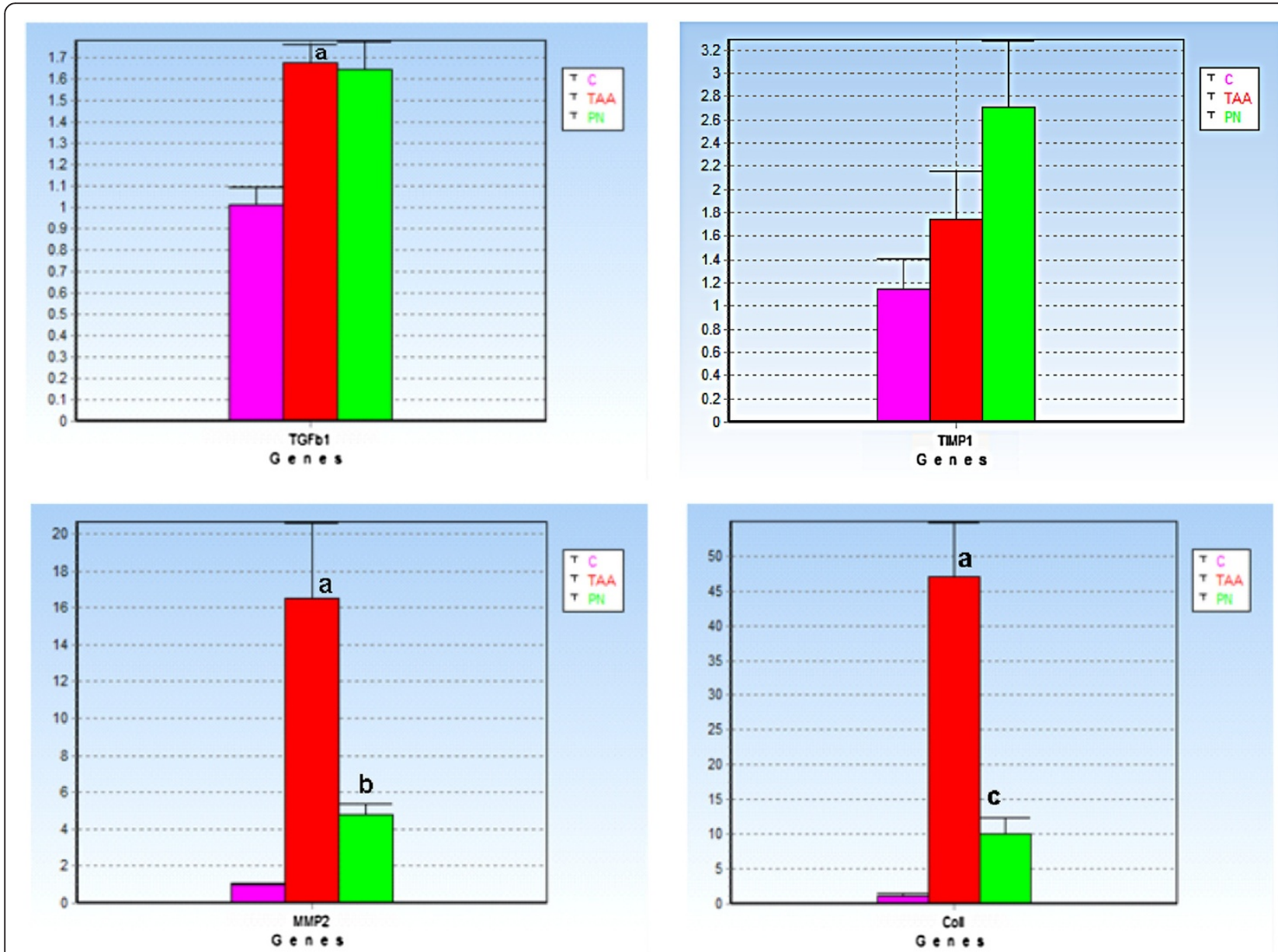

Figure 2 Real-time PCR analysis shows the relative fold changes of transforming growth factor beta (TGF $\beta$ ), matrix metalloproteinase 2 (MMP2), tissue inhibitors of metalloproteinases 1 (TIMP1), and collagen alpha (Colla1) between all experimental groups. Values

expressed as the mean \pm S.E.M. Different superscripts state significant differences. (a) Indicates significance versus the Normal group at $P \leq 0.05$; (b) indicates significance versus the TAA-treated group at $P \leq 0.05$ and (c) indicates significance versus the TAA-treated group at $P \leq 0.01$. 


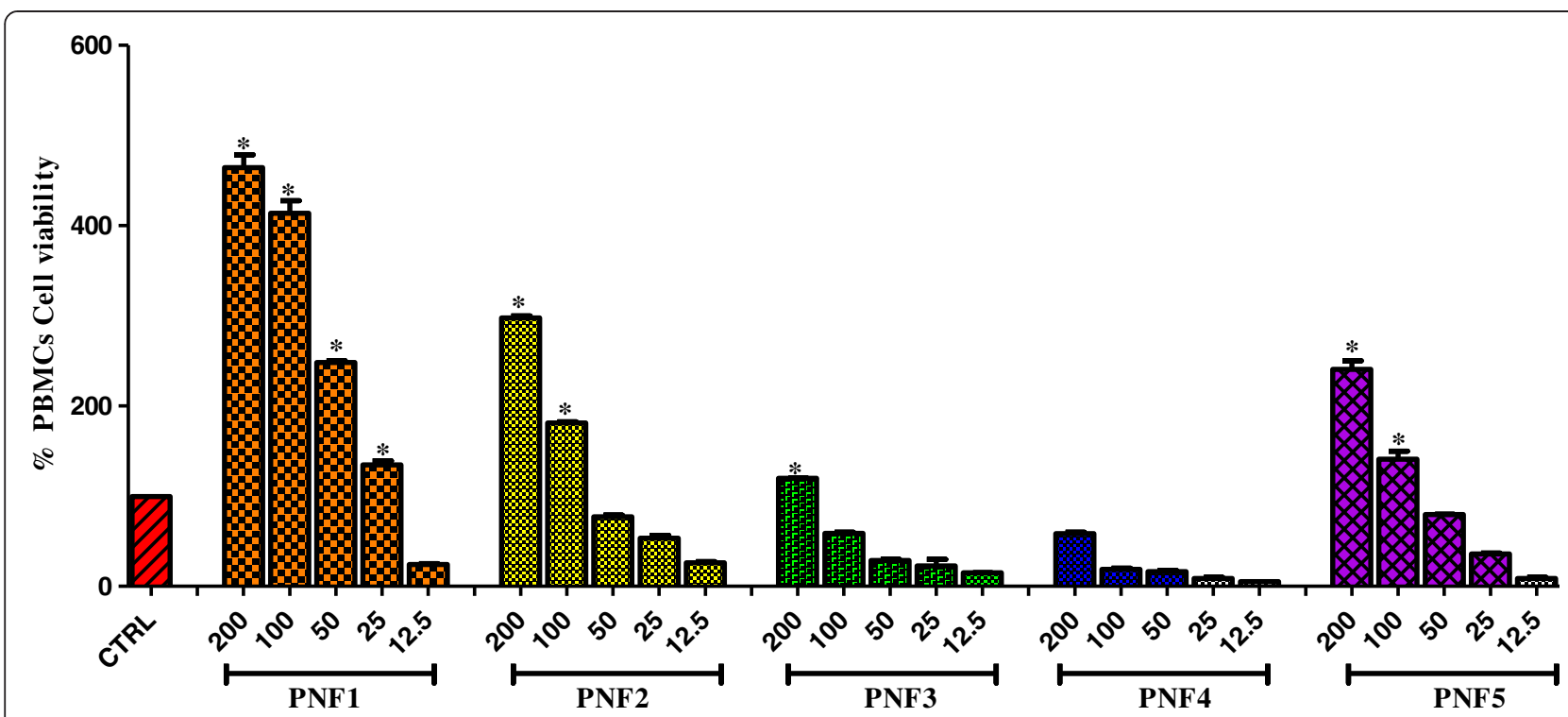

Phyllanthus niruri's Fractions

Figure 3 The effects of $P$. niruri fractions on human peripheral blood mononuclear cell (PBMC) proliferation. Data are expressed as the mean \pm SEM for triplicates; $(*)$ indicates significance versus the control group $\left(\mathrm{CTRL}=\mathrm{dH} \mathrm{H}_{2} \mathrm{O}\right)$ at $P \leq 0.05$.

as a percent of viability to proliferate PMBCs; the fraction with the highest activity was PNF1.

LC/MS was performed on the PNF1 fraction, which exhibited higher activity to proliferate the PBMCs. Subsequently, by LC/MS/MS using the positive ionization mode, four peaks were observed from PNF1 (Figures 4, 5, 6 and Table 1). However, only peak numbers 2 and 4 were identified. Peak number $2(\mathrm{RT}=4.454 \mathrm{~min}, \lambda=$ 221 and $280 \mathrm{~nm}, \mathrm{MW}=355$ ) (Figure 5) had $[\mathrm{M}+\mathrm{H}]^{+}$ at $m / z 356$ and was identified as caffeoylquinic acid

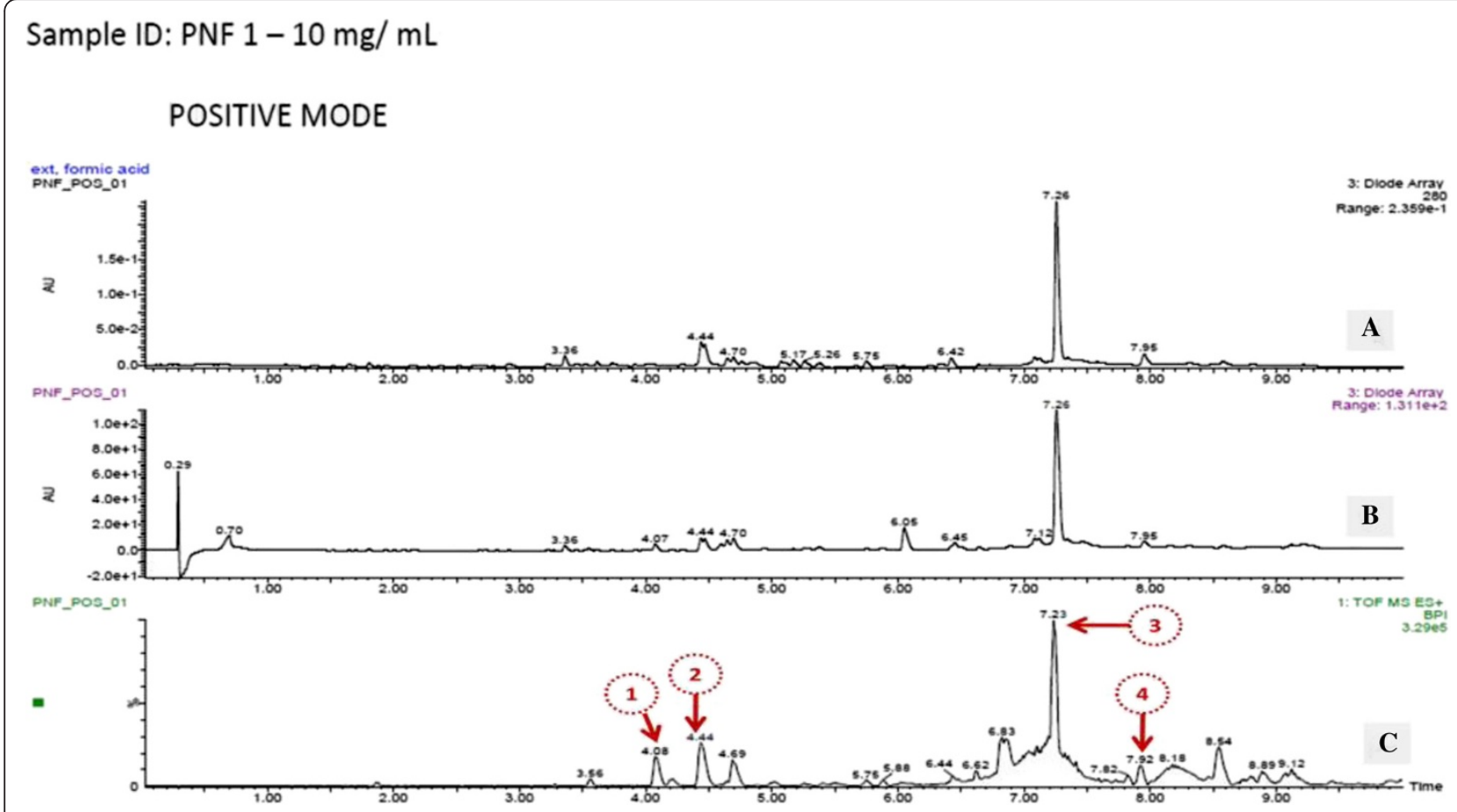

Figure 4 LC-TOF/MS and UV diode array chromatograms of $P$. niruri fraction 1 (PNF1); (A) UV diode array spectra at $280 \mathrm{~nm}$ (B) UV diode array spectra at a range between 190 and $800 \mathrm{~nm}$ (C) TOF/MS peaks in the positive mode ionization. 


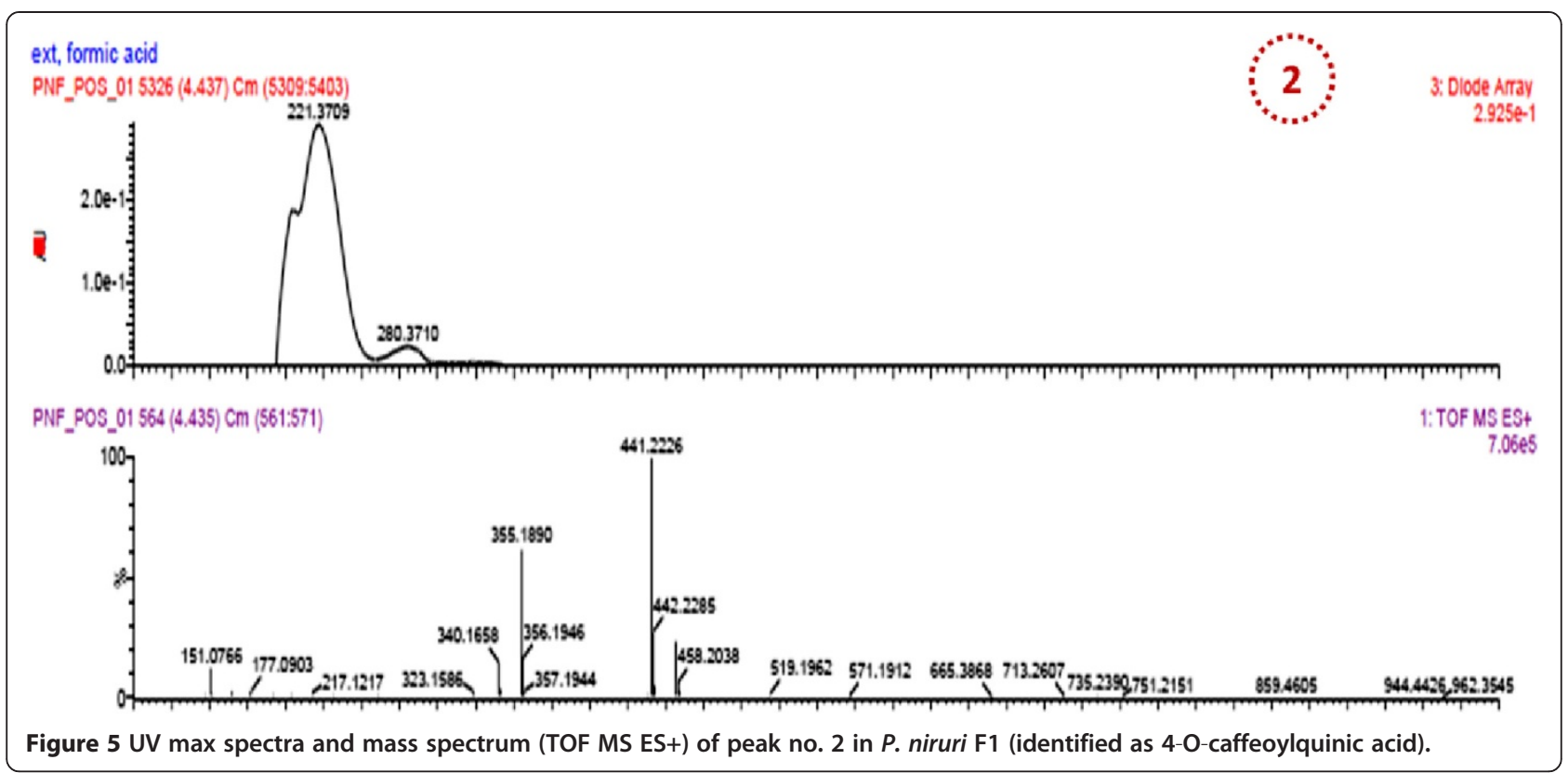

(an isomer of chlorogenic acid) with fragments at $\mathrm{m} / \mathrm{z}$ 340 (loss of $\mathrm{CH}_{3}$ ) and predominant fragments at $\mathrm{m} / \mathrm{z}$ $191,165,151$, and 147. Peak number 4 (Figure 6) $(\mathrm{RT}=$ $7.96 \mathrm{~min}, \lambda=225 \mathrm{~nm}, \mathrm{MW}=448)$ had $\left[\mathrm{M}+\mathrm{H}-\mathrm{H}_{2} \mathrm{O}\right]^{+}$ at $m / z 430$ and was identified as quercetin 3-O-rhamnoside with the loss of $\mathrm{H}_{2} \mathrm{O}$, and with the loss of rhamnoside, the ion appeared at $\mathrm{m} / \mathrm{z} 303$ and was identified as quercetin with other fragments at $m / z 219,205$ and 165 $[13,14]$.

\section{Discussion}

The objective of this study was to determine the roles of transforming growth factor $\beta$ (TGF $\beta 1$ ), metalloproteinase-2 (MMP2), collagen $\alpha \mathrm{I}$ (Coll $\alpha 1$ ) and tissue inhibitor of

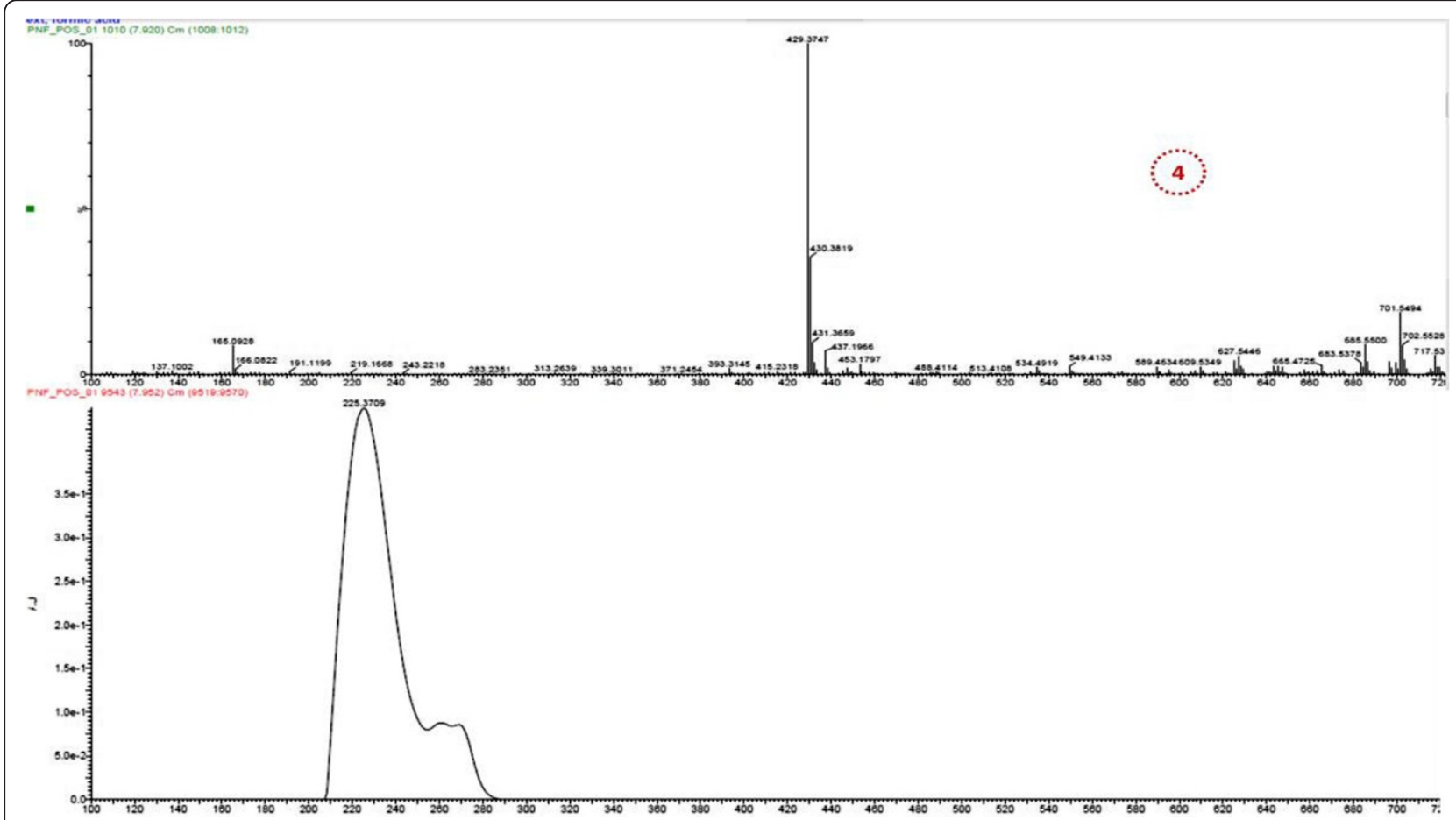

Figure 6 UV max spectra and mass spectrum (TOF MS ES+) of peak no. 4 in P. niruri F1 (identified as quercetin 3-O-rhamnoside). 
Table 1 Putative identification of main components of $\boldsymbol{P}$. niruri's active fraction

\begin{tabular}{ccccccccc}
\hline Plant fraction & Rt.time $(\mathbf{m i n})$ & $\boldsymbol{\lambda}(\mathbf{n m})$ & Molecular weight & $\mathbf{[ M}+\mathbf{H}] \mathbf{m} / \mathbf{z}$ & $\mathbf{M S} / \mathbf{M S}$ fragmentation & Tentative identification & Molecular formula \\
\hline PNF1 & 4.437 & 221,280 & 355 & 356 & $340,191,165,151,147$ & 4-O-Caffeolquinic acid & $\mathrm{C}_{16} \mathrm{H}_{18} \mathrm{O}_{9}$ \\
& 7.92 & 225 & 448 & 430 & $303,219,205,165$ & Quercetin3-O-rhamnoside & $\mathrm{C}_{21} \mathrm{H}_{20} \mathrm{O}_{11}$ \\
\hline
\end{tabular}

metalloproteinase-1 (TIMP1) in preventing thioacetamideinduced liver cirrhosis in rats.

These results demonstrated that the mRNA expression levels of TGF $\beta 1$, Coll $\alpha 1$, MMP2, and TIMP1 were unchanged in the control group; this supports the hypothesis that hepatic satellite cells (HSCs) were still in their quiescent state. However, these HSCs were activated by the presence of TAA and led to the high production of ECM and consequently high expression of TGF $\beta$, Collo1, MMP2, and TIMP1.

PN treatment successfully prevented the high synthesis of ECM and reduced the mRNA expression of TGF $\beta$, Coll $\alpha 1$, and MMP2 compared with the TAA-treated group.

Most studies of human liver diseases and animal models of progressive fibrosis have demonstrated that TIMP1 mRNA expression was upregulated at early stages of fibrosis and because TIMP1 functions not only reduce MMP activity but also act on the suppression of apoptosis by HSCs [15]. In our findings, hepatic reduction in TIMP1 mRNA expression in the TAA-treated group can be explained as a consequence of increased HSC apoptosis [16].

Figure 7 shows the putative mechanism of the alteration of mRNA levels of the investigated genes in TAA- treated rats. First, TAA bioactivates into thioacetamideS-oxide and other ROSs $[17,18]$, and activates the HSCs, which, in turn releases more ECM and subsequently increases TGF $\beta$ gene expression that affects the release of collagen $\alpha$ and MMP1 and then TIMP1. Therefore, scar tissue develops, and the liver losses its normal functions, anatomical shape and architecture $[19,20]$. Treatment with PN significantly reduced the effect of thioacetamide toxicity as follows: 1) removing the causative stimuli of TAA, neutralizing ROSs by their high antioxidant content and attenuating endogenous antioxidant enzymes to their normal levels; 2) maintaining HSCs in their quiescent state; and 3) increasing the release of TIMP1 to counter balance MMP2 and complete remodeling of the hepatocyte cellular system that preserves or sustains normal liver function, shape, and appearance.

These findings confirm the previous findings of Wills and Asha [21] who suggested that the hepatoprotective role of Lygodium flexuosum plant extract is because of the reduced mRNA levels of growth factors, proinflammatory cytokines, and other signaling molecules, which are involved in hepatic fibrosis including TGF $\beta 1$, procollagen-I, and TIMP1. Additionally, Chen et al. [22] demonstrated the hepatoprotective effects of

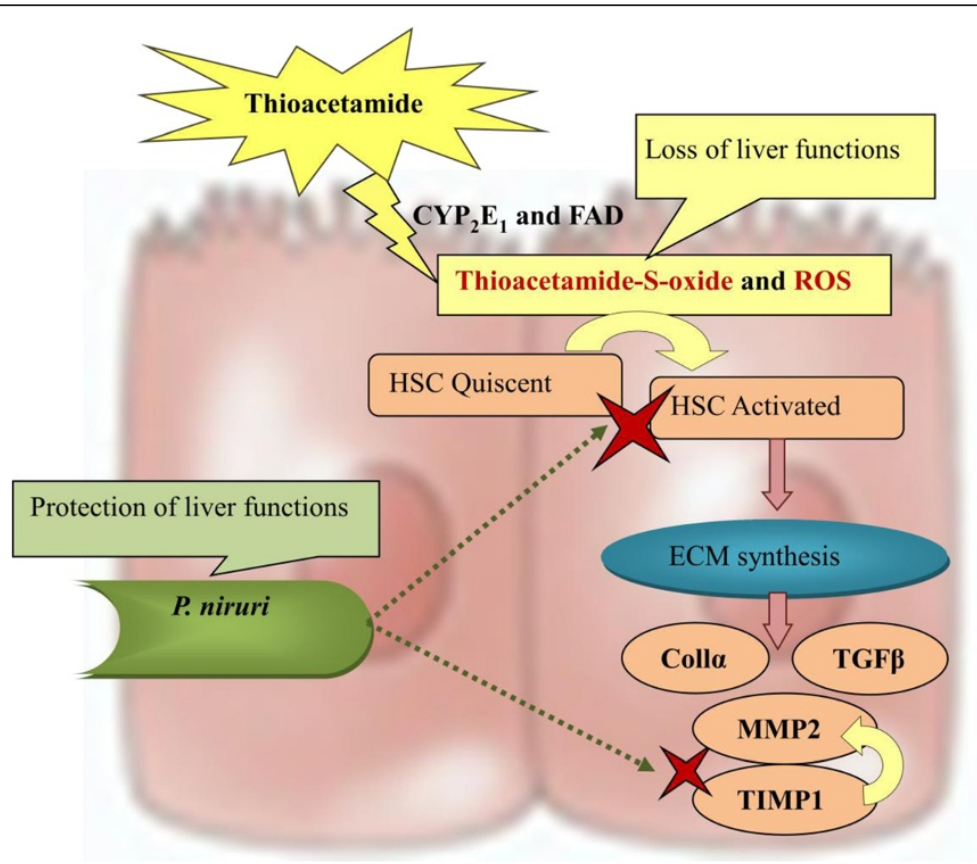

Figure 7 Putative mechanism of Phyllanthus niruri hepatoprotective effect as a response to TAA-induced hepatotoxicity. 
silymarin against TAA-induced liver damage to be caused by downregulation of hepatic MMP2, TIMP1, TGF $\beta 1, C O L \alpha 1$ and other genes in the mouse model of chronic liver fibrosis. Although the antifibrotic and hepatoprotective properties of the silibinin-phosphatidylcholine-vitamin E complex in the rat model of liver fibrosis stimulated by bile duct ligation and dimethylnitrosamine administration have been postulated to cause reduced mRNA expression levels of procollagen type I, TGF $\beta 1$, TIMP1, and MMP2, the administration of the complex has also been reported to reduce hepatic stellate cell activation and proliferation with collagen deposition [23].

The isolated chemical constituents included in P. niruri (4-O-caffeoylquinic acid and quercetin 3-O-rhamnoside) can further interpret the abovementioned hepatoprotective activity. 4-O-Caffeoylquinic acid, which is classified as a tannin, has been isolated previously from $P$. niruri and proven to possess antioxidant, immunomodulatory, and hepatoprotective effects in several in vivo and in vitro assays [24-26]. However, quercetin 3-O-rhamnoside belongs to the flavonoid group of compounds that exhibits a wide range of pharmacological benefits including antimicrobial, antiviral, antioxidant, gastroprotective, hepatoprotective, anti-inflammatory and chemopreventive effects [27-30]. Moreover, potential working mechanisms of flavonoids during injuries and tissue damage include the following: the interference of $\geq 3$ different free radical producing systems and an increase in function of the endogenous antioxidants CAT, SOD, and GPX [31]. Quercetin 3-O-rhamnoside has been confirmed in Phyllanthus species and other species of the Euphorbiaceae family [32-34]. Finally, both isolated chemical compounds from $P$. niruri (tannins and flavonoids) are classified as "polyphenols", which are one of the most frequent and ever-present groups of plant metabolites, and have an important role in human and animal diets [35]. Recent studies have shown that plant-derived polyphenols are promising nutraceuticals for the control of various disorders, such as cardiovascular, neurological, and neoplastic diseases [36]. In addition, plant-derived polyphenolic compounds have hepatoprotective activity against different types of liver damage inducers, such as $\mathrm{CCL}_{4}$ [37], paracetamol [38], and thioacetamide [39], which explains the high interest and initiation of many studies to evaluate the biological activity and bioavailabilities of polyphenolic compounds.

\section{Conclusion}

This present study contributes significant knowledge to our understanding of the mechanism that underlies the hepatoprotective effect of Phyllanthus niruri, which is suggested to be through the regulation of TGF $\beta$, Collo1, MMP2, and TIMP1 genes expression. The isolated chemical compounds (4-O-caffeoylquinic acid and quercetin 3-O-rhamnoside) of Phyllanthus niruri might have direct consequences for hepatoprotective activity. Therefore, promising approaches from this study must focus on TGF $\beta$, Collo1, MMP2, and TIMP1 genes expression to develop new therapy for the treatment of liver cirrhosis.

\section{Competing interests}

The authors declare that they have no competing interests.

\section{Authors' contributions}

Conceived and designed the experiments: ZA MS, performed the experiments: ZA MS, analyzed the data: ZA MS MK, contributed reagents/ materials/analysis tools: MA HM ZA MS, wrote and revised the paper: ZA MA. All authors read and approved the final manuscript.

\section{Acknowledgements}

The authors express gratitude to the University of Malaya for the financial supports PV047/2011B, Um.c/625/1/HIR (151) and FL011-2012.

\section{Author details}

'Department of Pharmacognosy, College of Pharmacy, Hawler Medical University, Erbil 44001, Iraq. ${ }^{2}$ Department of Pharmacology, Faculty of Medicine, University of Malaya, Kuala Lumpur 50603, Malaysia. ${ }^{3}$ Department of Anesthesiology, Faculty of Medicine, University of Malaya, Kuala Lumpur 50603, Malaysia. ${ }^{4}$ Department of Chemistry, Faculty of Science, University of Malaya, Kuala Lumpur 50603, Malaysia. ${ }^{5}$ Department of Biomedical Science, Faculty of Medicine, Kuala Lumpur 50603, Malaysia.

Received: 26 January 2013 Accepted: 1 July 2013

Published: 5 July 2013

\section{References}

1. Ong H, Norzalina J: Malay herbal medicine in Gemencheh, Negri Sembilan, Malaysia. Fitoterapia 1999, 70(1):10-14.

2. Freitas $A$, Schor N, Boim M: The effect of Phyllanthus niruri on urinary inhibitors of calcium oxalate crystallization and other factors associated with renal stone formation. BJU Int 2002, 89(9):829-834.

3. Boim MA, Heilberg IP, Schor N: Phyllanthus niruri as a promising alternative treatment for nephrolithiasis. Int Braz J Urol 2010, 36(6):657-664.

4. Barros ME, Lima R, Mercuri LP, Matos JR, Schor N, Boim MA: Effect of extract of Phyllanthus niruri on crystal deposition in experimental urolithiasis. Urol Res 2006, 34(6):351-357.

5. Murugaiyah V, Chan KL: Mechanisms of antihyperuricemic effect of Phyllanthus niruri and its lignan constituents. J Ethnopharmacol 2009, 124(2):233-239.

6. Harish R, Shivanandappa T: Antioxidant activity and hepatoprotective potential of Phyllanthus niruri. Food Chem 2006, 95(2):180-185.

7. Manjrekar A, Jisha V, Bag P, Adhikary B, Pai M, Hegde A, Nandini M: Effect of Phyllanthus niruri Linn. treatment on liver, kidney and testes in $\mathrm{CCl} 4$ induced hepatotoxic rats. Indian J Exp Biol 2008, 46(7):514-520.

8. Bhattacharjee R, Sil P: Protein isolate from the herb, Phyllanthus niruri L. (Euphorbiaceae), plays hepatoprotective role against carbon tetrachloride induced liver damage via its antioxidant properties. Food Chem Toxicol 2007, 45(5):817-826.

9. Amin ZA, Bilgen M, Alshawsh MA, Ali HM, Hadi AHA, Abdulla MA: Protective Role of Phyllanthus niruri Extract against ThioacetamideInduced Liver Cirrhosis in Rat Model. Evidence-Based Complementary and Alternative Medicine 2012, 2012

10. Zahra AA, Kadir FA, Mahmood AA, AA A h, Suzy SM, Sabri SZ, Latif II, Ketuly K: Acute toxicity study and wound healing potential of Gynura procumbens leaf extract in rats. Journal of Medicinal Plants Research 2011, 5(12):2551-2558.

11. Alshawsh MA, Abdulla MA, Ismail S, Amin ZA: Hepatoprotective Effects of Orthosiphon stamineus Extract on Thioacetamide-Induced Liver Cirrhosis in Rats. Evidence-based Complementary and Alternative Medicine: eCAM 2011, 2011 
12. Fraga CG, Martino VS, Ferraro GE, Coussio JD, Boveris A: Flavonoids as antioxidants evaluated by in vitro and in situ liver chemiluminescence. Biochem Pharmacol 1987, 36(5):717-720.

13. Bravo L, Goya L, Lecumberri E: LC/MS characterization of phenolic constituents of mate (llex paraguariensis, St. Hil.) and its antioxidant activity compared to commonly consumed beverages. Food Res Int 2007, 40(3):393-405

14. Seeram NP, Lee R, Scheuller HS, Heber D: Identification of phenolic compounds in strawberries by liquid chromatography electrospray ionization mass spectroscopy. Food Chem 2006, 97(1):1-11.

15. Yoshiji H, Kuriyama S, Yoshii J, Ikenaka Y, Noguchi R, Nakatani T, Tsujinoue H, Yanase K, Namisaki T, Imazu H: Tissue inhibitor of metalloproteinases-1 attenuates spontaneous liver fibrosis resolution in the transgenic mouse. Hepatology 2002, 36(4):850-860.

16. Arthur MJP: Fibrogenesis II. Metalloproteinases and their inhibitors in liver fibrosis. American Journal of Physiology-Gastrointestinal and Liver Physiology 2000, 279(2):G245-G249.

17. Chilakapati J, Shankar K, Korrapati MC, Hill RA, Mehendale HM: Saturation toxicokinetics of thioacetamide: role in initiation of liver injury. Drug Metab Dispos 2005, 33(12):1877-1885.

18. Yogalakshmi B, Viswanathan P, Anuradha CV: Investigation of antioxidant, anti-inflammatory and DNA-protective properties of eugenol in thioacetamide-induced liver injury in rats. Toxicology 2010, 268(3):204-212.

19. Wang H, Zhao YP, Gao CF, Ji Q, Gressner AM, Yang ZX, Weiskirchen R: Transforming growth factor $\beta 1$ gene variants increase transcription and are associated with liver cirrhosis in Chinese. Cytokine 2008, 43(1):20-25.

20. Mormone $\mathrm{E}$, George J, Nieto N: Molecular pathogenesis of hepatic fibrosis and current therapeutic approaches. Chem Biol Interact 2011, 193(3):225-231.

21. Wills $P$, Asha V: Protective mechanism of Lygodium flexuosum extract in treating and preventing carbon tetrachloride induced hepatic fibrosis in rats. Chem Biol Interact 2007, 165(1):76-85.

22. Chen IS, Chen YC, Chou CH, Chuang RF, Sheen LY, Chiu CH: Hepatoprotection of silymarin against thioacetamide-induced chronic liver fibrosis. J Sci Food Agric 2012, 92(7):1441-1447.

23. Di Sario EB A, Taffetani S, Omenetti A, Candelaresi C, Marzioni M, De Minicis S, Benedetti A: Hepatoprotective and antifibrotic effect of a new silybinphosphatidylcholine-Vitamin E complex in rats. Dig Liver Dis 2005, 37:869-876.

24. Silva BM, Andrade PB, Valentão P, Ferreres F, Seabra RM, Ferreira MA: Quince (Cydonia oblonga Miller) fruit (pulp, peel, and seed) and jam: antioxidant activity. J Agric Food Chem 2004, 52(15):4705-4712.

25. Adzet T, Camarasa J, Laguna JC: Hepatoprotective activity of polyphenolic compounds from Cynara scolymus against $\mathrm{CCl} 4$ toxicity in isolated rat hepatocytes. J Nat Prod 1987, 50(4):612-617.

26. Kapil A, Koul I, Suri O: Antihepatotoxic effects of chlorogenic acid from Anthocephalus cadamba. Phytother Res 1995, 9(3):189-193.

27. Kähkönen MP, Hopia Al, Vuorela HJ, Rauha JP, Pihlaja K, Kujala TS, Heinonen M: Antioxidant activity of plant extracts containing phenolic compounds. J Agric Food Chem 1999, 47(10):3954-3962.

28. Zayachkivska O, Konturek S, Drozdowicz D, Konturek P, Brzozowski T, Ghegotsky M: Gastroprotective effects of flavonoids in plant extracts. J Physiol Pharmacol 2005, 56(Suppl 1):219-231.

29. Ozcelik B, Orhan I, Toker G: Antiviral and antimicrobial assessment of some selected flavonoids. Zeits Chrift Fur Natur Forschung C 2006, 61(9/10):632.

30. Oh H, Kim DH, Cho JH, Kim YC: Hepatoprotective and free radical scavenging activities of phenolic petrosins and flavonoids isolated from $<i>$ Equisetum arvense</i>. J Ethnopharmacol 2004, 95(2):421-424.

31. Nijveldt RJ, van Nood E, van Hoorn DEC, Boelens PG, van Norren K, van Leeuwen PAM: Flavonoids: a review of probable mechanisms of action and potential applications. Am J Clin Nutr 2001, 74(4):418-425.

32. Zhang YJ, Abe T, Tanaka T, Yang CR, Kouno I: Two new acylated flavanone glycosides from the leaves and branches of Phyllanthus emblica. Chem Pharm Bull 2002, 50(6):841-843.

33. Calixto JB, Santos A, Cechinel FV, Yunes RA: A review of the plants of the genus Phyllanthus: their chemistry, pharmacology, and therapeutic potential. Medicinal research reviews 1998, 18(4):225.

34. Kuti JO, Konuru HB: Antioxidant capacity and phenolic content in leaf extracts of tree spinach (Cnidoscolus spp.). J Agric Food Chem 2004, 52(1):117-121.
35. Bravo L: Polyphenols: chemistry, dietary sources, metabolism, and nutritional significance. Nutr Rev 1998, 56(11):317-333.

36. Ullah MF, Khan MW: Food as medicine: potential therapeutic tendencies of plant derived polyphenolic compounds. Asian Pac J Cancer Prev 2008, 9(2):187-196.

37. Shimoda H, Tanaka J, Kikuchi M, Fukuda T, Ito H, Hatano T, Yoshida T: Walnut polyphenols prevent liver damage induced by carbon tetrachloride and d-galactosamine: hepatoprotective hydrolyzable tannins in the kernel pellicles of walnut. J Agric Food Chem 2008, 56(12):4444-4449.

38. Chen X, Sun CK, Han GZ, Peng JY, Li Y, Liu YX, Lv YY, Liu KX, Zhou Q, Sun HJ: Protective effect of tea polyphenols against paracetamol-induced hepatotoxicity in mice is significanly correlated with cytochrome P450 suppression. World journal of gastroenterology: WJG 2009, 15(15):1829.

39. Madani H, Talebolhosseini M, Asgary S, Naderi G: Hepatoprotective activity of Silybum marianum and Cichorium intybus against thioacetamide in rat. Pak J Nutr 2008, 7(1):172-176.

doi:10.1186/1472-6882-13-160

Cite this article as: Amin et al:: Gene expression profiling reveals underlying molecular mechanism of hepatoprotective effect of Phyllanthus niruri on thioacetamide-induced hepatotoxicity in Sprague Dawley rats. BMC Complementary and Alternative Medicine 2013 13:160.

\section{Submit your next manuscript to BioMed Central and take full advantage of:}

- Convenient online submission

- Thorough peer review

- No space constraints or color figure charges

- Immediate publication on acceptance

- Inclusion in PubMed, CAS, Scopus and Google Scholar

- Research which is freely available for redistribution 